\title{
Disease gene mapping in isolated human populations: the example of Finland
}

\author{
Albert de la Chapelle
}

The recent surge of interest in isolated human populations can be attributed largely to the advances in molecular genetics that now appear to produce an endless array of new data. However, the organised study of inherited traits and disorders in isolated populations started several decades ago. For example, at the beginning of the second half of this century several enthusiastic investigators at the Department of Paediatrics, University of Helsinki began to document rare diseases in Finns that either had not been previously described or were very rare elsewhere. The 'flagship' disease was congenital nephrosis described by Hallman et $a^{1}$ and established as an autosomal recessive disorder by Norio. ${ }^{2}$ These were the heydays of biochemical genetics. Rapidly, as many as a dozen rare disorders, many of which were 'metabolic', were found with a high frequency in Finns. A landmark paper by Norio et $a l^{3}$ carrying the title Hereditary diseases in Finland; rare flora in rare soil was published in 1973; it described 10 'Finnish' disorders. Another landmark paper had appeared a year earlier describing extensive blood group and serum marker studies in conjunction with genealogical features of the Finnish population. ${ }^{4}$ Further studies by Nevanlinna and his group have characterised the Finnish gene pool and offered interpretations regarding the Finnish population history and structure. ${ }^{5-8}$ The following is a brief review of 'Finnish' disease genes and the lessons that have been gained so far from their molecular study.

\begin{abstract}
A heritage
The term 'Finnish Disease Heritage' coined by Drs Norio, Nevanlinna, and Perheentupa denotes those Mendelian disorders that fulfil the somewhat arbitrary definition of being much more prevalent in Finland than in most other populations. Table 1 lists 27 such autosomal recessive disorders while in table 2 two autosomal dominant and two $\mathrm{X}$ chromosomal recessive disorders are listed.

How accurate are the quoted numbers of known cases? First, all figures are by necessity underestimates rather than overestimates. Second, the figures from Finland are much closer to reality than those from elsewhere in great part because the Finnish figures comprise unpublished cases in addition to
\end{abstract}

published ones. Moreover, ascertainment is usually more complete in Finland than in many other populations. Third, not surprisingly, recent evidence suggests that the figures for cases 'elsewhere' will often turn out to be much higher. For instance, retinoschisis is increasingly diagnosed in unrelated patients worldwide, ${ }^{13}$ progressive myoclonus epilepsy appears to be quite prevalent in the Mediterranean region, ${ }^{14}$ and congenital chloride diarrhoea occurs with high frequency in Poland ${ }^{15}$ and around the Persian Gulf. ${ }^{16}$ In conclusion, however, most of the disorders listed in tables 1 and 2 show remarkably high incidences in Finland relative to most other populations.

\section{Population development: the 'founding' of Finland}

Documented history in Finland begins approximately 1000 years ago so that much of our knowledge is based on archaeology. Undisputed archaeological evidence exists of human presence in Finland soon after the last glacial period that ended some 11000 years ago. ${ }^{17}$ As agriculture spread northwards from the Middle East, ${ }^{18}$ southern Finland was one of the last regions of Europe to be reached. Agriculture started 4000 to 5000 years ago in southern Finland, and several archaeologically defined distinct human cultures followed in subsequent centuries and millennia. Anthropologically these populations were Europoid; ethnologically they were of Finnic and Germanic origin. The numbers of people at different times cannot be estimated by archaeological methods. It is clear, however, that the major expansion that has led to the present population started some 2000 to 2500 years ( 80 to 100 generations) ago. This coincided with increased immigration by Baltic Finns and Germanic peoples that lasted a few hundred years. Thus, the 'founders' of Finland can be viewed as a mixture of preexisting populations and immigrants. A crucial question concerns the number of persons at the beginning of the expansion, the founders. Archaeological evidence favours very limited numbers and as the entire population in 1500 after considerable expansion has been estimated to be only $250000,{ }^{5}$ the founders can only have been very few in number. Population bottlenecks before historical times can 
Table 1 Autosomal recessive disorders that are much more common in Finland than in most other populations.

\begin{tabular}{|c|c|c|c|c|}
\hline \multirow[b]{2}{*}{ Disorder } & \multirow{2}{*}{$\begin{array}{l}\text { Gene } \\
\text { symbol }\end{array}$} & \multirow{2}{*}{$\begin{array}{l}\text { McKusick } \\
\text { No }\end{array}$} & \multicolumn{2}{|c|}{$\begin{array}{l}\text { Approximate number } \\
\text { of affected described }\end{array}$} \\
\hline & & & Finland & Elsewhere \\
\hline Aldolase B deficiency; hereditary fructose intolerance & ALDOB & 229500 & 30 & $>100$ \\
\hline Arthrogryposis multiplex congenita with pulmonary hypoplasia; also Pena-Shokeir syndrome, type I & & 208150 & $31^{*}$ & $<100^{*}$ \\
\hline Aspartylglucosaminuria & AGA & 208400 & $>200$ & 20 \\
\hline Cartilage-hair hypoplasia; also metaphyseal chondrodysplasia, McKusick type & $\mathrm{CHH}$ & 250250 & 112 & $80^{+}$ \\
\hline Cohen syndrome & & 216550 & 20 & $<100^{*}$ \\
\hline Congenital chloride diarrhoea & CLD & 214700 & 40 & $>60$ \\
\hline Congenital nephrosis; also Finnish nephrosis & & 256300 & 300 & $>200$ \\
\hline Cornea plana congenita & & 217300 & 60 & $>20$ \\
\hline Diastrophic dysplasia & DTD & 222600 & 170 & 200 \\
\hline Dibasicaminoaciduria II (lysinuric protein intolerance, LPI) & & 222700 & 32 & $<20$ \\
\hline Disaccharide intolerance II; also congenital lactase deficiency & & 223000 & 20 & $<20$ \\
\hline Gonadal dysgenesis, XX type & & 233300 & 75 & $<100$ \\
\hline Gyrate atrophy of choroid and retina; also gyrate atrophy with ornithine-delta-amino transferase deficiency & OAT & 258870 & 70 & $<50$ \\
\hline $\begin{array}{l}\text { Hydrolethalus syndrome } \\
\text { Hypoadrenocorticism with hypoparathyroidism and superficial moniliasis; also autoimmune }\end{array}$ & & 236680 & 60 & 20 \\
\hline $\begin{array}{l}\text { Hypoadrenocorticism with hypoparathyroidism and superficial moniliasis; also autoimmune } \\
\text { polyendocrinopathy-candidiosis-ectodermal dystrophy; APECED } \\
\text { Juvenile pernicious anaemia resulting from selective intestinal malabsorption of vitamin } \mathrm{B} 12 \text {, with }\end{array}$ & & 240300 & 63 & $<50$ \\
\hline proteinuria; also Imerslund-Gräsbeck syndrome & & 261100 & 30 & 30 \\
\hline Meckel syndrome & & 249000 & 100 & $>100$ \\
\hline Mulibrey nanism & & 253250 & 54 & $<10$ \\
\hline Muscle-eye-brain disease (MEB disease) & & 253280 & $21+$ & $<10$ \\
\hline $\begin{array}{l}\text { Neuronal ceroid-lipofuscinosis, infantile Finnish type; also Santavuori disease; Haltia-Santavuori disease }\end{array}$ & CLN1 & 256730 & $107^{+}$ & 50 \\
\hline Non-ketotic hyperglycinaemia; medium-chain(?)acyl-CoA-dehydrogenase deficiency & & 201450 & 27 & $<100$ \\
\hline OHAHA syndrome (ophthalmoplegia, hypacusis, ataxia, hypotonia, athetosis) & & 258120 & 12 & None \\
\hline PEHO syndrome (progressive encephalopathy with oedema, hypsarrhythmia, and optic atrophy) & & & 20 & 20 \\
\hline Progressive dementia with lipomembranous polycystic osteodysplasia & & 221770 & 21 & $<50$ \\
\hline Progressive myoclonus epilepsy, Unverricht-Lundborg type; also Baltic myoclonus & EPM1 & 254800 & 170 & $>100$ \\
\hline Salla disease; also sialuria, Finnish type & & 268740 & 68 & $<10$ \\
\hline Usher syndrome, type III; also retinitis pigmentosa and congenital deafness & USH3 & 176900 & 70 & $<100$ \\
\hline
\end{tabular}

* Phenotypic heterogeneity suggests two or more different diseases are involved.

$\dagger$ In addition a very high incidence occurs in the American Amish, with some 150 affected.

$\ddagger$ Phenotypically similar entities exist.

The data on disease frequency are from references 3 and 9-12. For some, but not for all, diseases the figures on frequency in Finland have been updated from various The data on disease frequency are from
published and unpublished sources.

only be inferred from archaeological findings, but during historical times, the last period of serious decline occurred between 1690 (population 600000 ) and 1730 (population some $250000)$. Thereafter growth has been rapid, the present number being 5 million.

\section{NON-FINNIC IMMIGRATION DURING THE EXPANSION}

Finland's eastern neighbour, Russia, has contributed only a little to the present gene pool. Based on archaeological evidence the main non-Finnic contribution comes from Sweden and other regions south-west of Finland dating back at least 4000 to 5000 years. Historical documentation begins with the Viking era (800-1100 AD) followed by Swedish crusades beginning in approximately 1150 . Swedish immigrants settling primarily in the coastal southern and western regions continued to arrive until approximately 1800. The 'Swedish', that is, Germanic, effects on the Finnish gene pool have been well documented by Nevanlinna and his group. ${ }^{58}$ The density of 'Swedish' gene markers shows a gradient from strongest in south-west Finland to weakest in the north-east. Most Finns have Scandinavian ancestry resulting from gene diffusion, founder effects, or the direct introduction of genes throughout the population. ${ }^{5}$ Archaeological evidence amply supports this view. ${ }^{19}$

\section{LANGUAGE VERSUS GENES}

Finnish is one of the Finno-Ugric languages originating in the Western Uralic region. Present day European members of this language group comprise Hungarian, Estonian, Finnish, and Saame (Lappish). As far as is known there is little evidence of any genetic links between, for example, the present Hungarian and Finnish populations. Linguistic and genetic relatedness often coincide ${ }^{2021}$ but in the case of Hungarians and Finns this does not appear to be the case. However, the historical and geographical proximity of the Estonian and Finnish populations suggests that they share many genes, and this has been shown for markers. ${ }^{7}$ Whether or not they also share those disease gene frequencies that are the subject of this review still needs exploring, however.

\section{POPULATION DEVELOPMENT INSIDE FINLAND} AFTER THE FOUNDING

Archaeological and historical documentation conclusively shows that the founding popula-

Table 2 Autosomal dominant and $X$ chromosomal disorders that are much more common in Finland than in most other populations.

\begin{tabular}{|c|c|c|c|c|}
\hline \multirow[b]{2}{*}{ Disorder } & \multirow{2}{*}{$\begin{array}{l}\text { Gene } \\
\text { symbol }\end{array}$} & \multirow{2}{*}{$\begin{array}{c}\text { McKusick } \\
\text { No }\end{array}$} & \multicolumn{2}{|c|}{$\begin{array}{l}\text { Approximate number } \\
\text { of affected described }\end{array}$} \\
\hline & & & Finland & Elsewhere \\
\hline $\begin{array}{l}\text { Familial amyloidosis, Finnish type, FAF; also } \\
\text { Meretoja syndrome; also amyloidosis V } \\
\text { Familial benign erythrocytosis } \\
\text { Choroideremia } \\
\text { Retinoschisis }\end{array}$ & $\begin{array}{l}\text { GSN } \\
\text { EPOR } \\
\text { CHM } \\
\text { RS }\end{array}$ & $\begin{array}{l}105120 \\
133100 \\
303100 \\
312700\end{array}$ & $\begin{array}{c}1000^{*} \\
40 \\
150 \\
300\end{array}$ & $\begin{array}{rl}<40 & ? \\
& 300 \\
> & 300\end{array}$ \\
\hline
\end{tabular}

* Estimate; some 300 actually diagnosed. 
tion expanded rapidly and spread over the area of 'early settlement' (fig 1). In contrast, the northern and eastern parts of the country ('late settlement', fig 1) remained relatively unpopulated until the 15th century when small numbers of people from southern and western Finland began to move into this vast area whose main population expansion began as late as the 17 th century. ${ }^{22}$ In part this occurred as a result of a royal decree that ordered people from the region of South Savo (fig 1) to go north. Thus many of the late settlement areas today represent a recently expanded subset of the 'general' Finnish population, a striking example of a second sampling bottleneck.

\section{CONCLUSION}

A greatly simplified population history depicts Finland's present day population of 5 million as being descended mainly from a small number of founders of Baltic Finnic and Germanic origin, whose main expansion began some 80 to 100 generations ago. The expanding population rapidly spread over the southern and western parts of the country. Later immigration, mainly from Sweden and the Baltic region, did occur but in numerical terms the population expansion after the 'founding' can be viewed as having occurred in remarkable isolation. Parts of the distant northern and north-eastern regions were settled thousands of years ago but the main expansion began only some 300 to 500 years ago, founded in part by a limited subset of the existing population.

\section{Autosomal dominant founding \\ mutations}

Common autosomal dominant mutations causing diseases such as achondroplasia usually show a high proportion of new mutations and therefore occur with similar frequencies in most populations. ${ }^{23}$ In contrast, rare dominantly inherited diseases can be highly enriched in isolated populations provided they do not confer selective disadvantage. A typical example is Finnish amyloidosis, also referred to as Meretoja disease. ${ }^{24}$ Manifestations mainly come from the cranial nerves and cornea leading to progressive facial disfiguration and reduced eyesight. There is no reduced fertility. Genealogical links have been found proving actual kinship between many affected subjects. A look at the map (fig 2) shows that the founder lived in one of two nearby parishes in southern Finland and a combination of genealogical and historical data led Meretoja ${ }^{2526}$ to speculate that the founder may have lived in the 1200 s; some 1000 persons are probably affected today. After it had been shown that the amyloid was derived from gelsolin (GSN), the mutation (Asp187Asn) in the Finnish population was established ${ }^{2728}$ and it was shown that it is caused by a G654A substitution in $\mathrm{GSN}^{29}$ As expected, all Finnish patients studied so far carry the same mutation. ${ }^{3031}$ Available evidence suggests that the disease is exceedingly rare, as fewer than 10 pedigrees comprising in total fewer than 40 affected subjects have been published worldwide. When the first two non-Finnish families had been tested (both living in the USA) and both had displayed the G654A mutation, ${ }^{3032}$ the hypothesis was put forward that most or all living patients world wide shared one ancestral mutation. However, another mutation, G654T, was subsequently found in a Danish and a Czech pedigree, and as these mutations occurred on different intragenic haplotypes it became evident that there had been more than one or two independent mutations. ${ }^{30}$ Moreover, as no mutations have so far been detected other than in nucleotide 654 (amino acid 187), it appears that specific alterations of this residue of the gelsolin molecule may predomi-

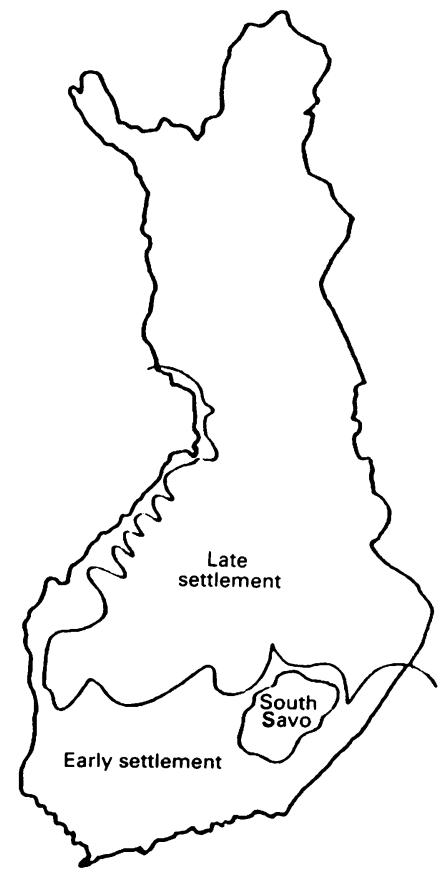

Figure 1 Map of Finland showing boundary between early and late settlement areas (from ref 10).

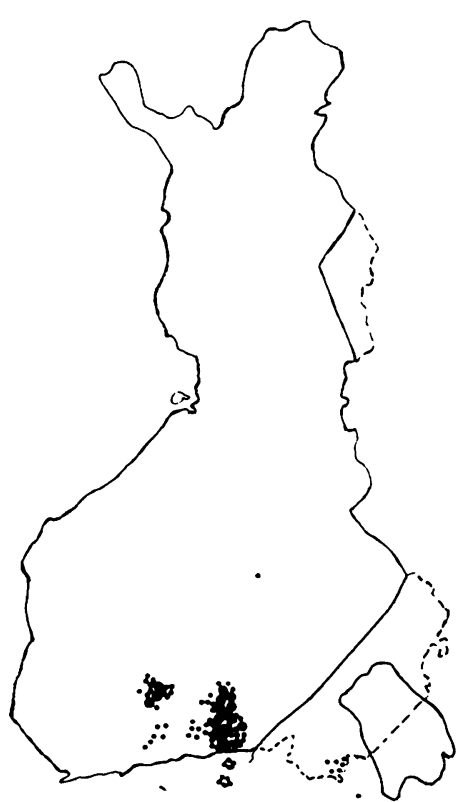

Figure 2 Map of Finland showing birth places of ancestors of patients with gelsolin derived amyloidosis (from ref 3). 
nantly or even uniquely predispose it to amyloidogenesis.

A recently mapped and molecularly characterised autosomal dominant character, benign erythrocytosis resulting from a mutation in the erythropoietin receptor (EPOR) gene, occurs in an extended pedigree comprising over 30 affected subjects in Finland ${ }^{3334}$ How widespread this mutation is in Finland is yet to be determined. Benign familial erythrocytosis of unknown aetiology is a rare condition worldwide. ${ }^{35}$ Sporadic occurrence as well as dominant and recessive inheritance have been invoked. It will be of interest to determine what proportion of these cases are caused by EPOR mutations and whether they resemble the one found in Finland.

In conclusion, dominant mutations that do not affect fertility may attain high gene frequencies in isolated, immobile populations and Finnish amyloidosis is a prime example.

\section{$X$ linked recessive founding mutations} In many severe $\mathrm{X}$ linked recessive conditions a high proportion of new mutations is associated with impaired reproduction. Such disorders usually occur with equal frequencies in all populations. Well known examples include Duchenne and Becker muscular dystrophy, haemophilia $A$ and $B$, and the fragile $X$ syndrome. Like autosomal dominant disorders, $X$ linked disorders without significantly reduced

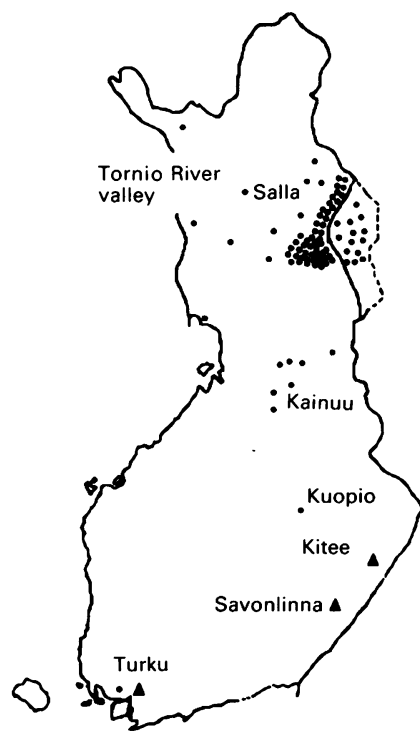

Figure 3 Map of Finland showing birth places of ancestors of patients with choroideremia (from ref 40 ).

Table 3 Haplotypes of markers flanking the CHM locus in CHM and non-CHM chromosomes from three different geographical clusters in northern Finland.

\begin{tabular}{|c|c|c|c|c|c|c|}
\hline \multirow[b]{2}{*}{ Haplotype } & \multicolumn{3}{|c|}{ CHM } & \multicolumn{3}{|c|}{ Non-CHM } \\
\hline & Salla & Kainuu & Tornio & Salla & Kainuu & Tornio \\
\hline $\begin{array}{l}\text { ABdEfg } \\
\text { abdEfg } \\
\text { AbdEfg } \\
\text { ABdEFg } \\
\text { aBdEfg } \\
\text { Abdefg } \\
\text { Other }\end{array}$ & $\begin{array}{r}62 \\
1 \\
1 \\
1\end{array}$ & 4 & 4 & $\begin{array}{l}5 \\
1 \\
9 \\
1\end{array}$ & 1 & 4 \\
\hline
\end{tabular}

Alleles emanate from RFLPs in loci flanking the CHM gene as follows: Aa, PGK1; Bb, DXS72; Dd, DXYS1; Ee DXYS5; Ff, DXYS4; Gg, DXYS12. For details see ref 42.
Table 4 RFLP alleles of intragenic marker $p Z 11$ associated with CHM and non-CHM chromosomes from three different geographical clusters in northern

Finland 43

\begin{tabular}{lccccc}
\hline & \multicolumn{2}{c}{ CHM } & & \multicolumn{2}{c}{ Non-CHM } \\
\cline { 2 - 3 } \cline { 5 - 6 } Location & Allele 1 & Allele 2 & & Allele 1 & Allele 2 \\
\hline Salla & 63 & 0 & & 46 & 68 \\
Kainuu & 0 & 4 & & 6 & 0 \\
Tornio & 5 & 0 & & 3 & 5 \\
\hline
\end{tabular}

reproduction may be widespread in isolated populations. Finland provides two illustrative examples, choroideremia and retinoschisis. In choroideremia (CHM) affected males have normal vision in childhood. The disease is first manifested in the teens as night blindness followed by reduced visual fields and reduced eyesight, leading to total or near total blindness in middle or older age. Carrier females have normal eyesight but have characteristic retinal findings and so can be accurately diagnosed by ophthalmoscopy..$^{36}$ Approximately 150 affected males have been diagnosed in Finland, while until recently some 250 patients had been reported worldwide. After the mapping and cloning of the CHM gene ${ }^{37}$ patients elsewhere are now being reported in increasing numbers. ${ }^{38}$

Two remarkably large CHM pedigrees are known in the world, one in Canada ${ }^{39}$ and one in northern Finland. ${ }^{936}$ The following is a brief account of how population genetics and haplotype analyses contributed to the study of CHM in northern Finland.

As is shown in fig 3, a total of five sporadic cases or small pedigrees with CHM is known in southern Finland. Genomic deletions are the cause of the disease in three. A very high prevalence of the disease occurs in northern Finland. By careful genealogical study many families could be connected to a super-pedigree whose likely founder couple were born in 1644 and 1646, 13 generations removed from the present youngest generation. ${ }^{936}$ Numerous descendants still live in the parish of Salla in the far north-east. However, CHM patients living some $250 \mathrm{~km}$ further south (in Kainuu) and others living some $250 \mathrm{~km}$ west (Tornio river valley) showed no demonstrable genealogical links to the Salla pedigree.

In early linkage analyses all pedigrees displayed linkage to the same locus. ${ }^{412}$ Haplotype analyses comprising six RFLP markers led to interesting observations (table 3 ). First, members of the same pedigree mostly had identical haplotypes as would be expected if they were closely related. Second, haplotypes were consistent within each of three different districts but differed from each other significantly. Two alternative interpretations were offered. ${ }^{4}$ First, different mutations could be involved, but this appeared unlikely in view of the rarity of the condition. Second, all patients might share a common ancestor, but recombinations had occurred after branching.

After the CHM gene had been defined a polymorphic intragenic marker, $\mathrm{pZ} 11$, was studied with the aim of determining if one or several mutations were involved in northern Finland. ${ }^{43}$ As shown in table 4 the CHM 
mutations in Salla and Tornio occur on chromosome carrying allele 1 while in Kainuu CHM is associated with allele 2 . Thus it appeared plausible that at least two mutations might account for the disease.

Definitive proof had to await the unravelling of the mutations themselves. It was first shown that all members of the Salla pedigree had the same unique mutation, CHM*SAL, consisting of an insertion of a $\mathrm{T}$ into a splice donor site leading to the transcriptional skipping of one exon followed by premature termination of translation. ${ }^{40}$ This mutation occurred in neither the Kainuu nor the Tornio patients, nor in two apparently unrelated patients from southern Finland. More recent data show that the mutations in Kainuu and Tornio do indeed differ from each other. ${ }^{44}$ Thus, in the small (500 000 persons) and isolated northern Finnish population, three different CHM mutations occur. While this high figure is possibly the result of chance alone, it needs to be considered that the frequency of three CHM mutations in a population of 500000 corresponds to $30 \mathrm{CHM}$ mutations in Finland (eight known) and 1800 in the USA (some 20 unrelated patients published so far).

\section{Linkage disequilibrium in a recently founded population}

The data in table 3 show almost total linkage disequilibrium between CHM and an extended RFLP haplotype within each of the three districts in northern Finland. This is remarkable as the genetic distance between the haplotype's outermost loci is of the order of $9 \mathrm{cM}^{42}$

While linkage disequilibrium in large panmictic populations rarely, if ever, is discernible at genetic distances exceeding $1 \mathrm{cM},{ }^{45}$ we show empirically here that, as expected, recently founded populations will show linkage disequilibrium over much longer stretches of DNA. As will be detailed below the genetic distances between loci can be calculated based on linkage disequilibrium as long as the population fulfils certain criteria. In this case the crucial point is the number of generations since the founding. Based on the genealogical evidence on CHM in Salla it was calculated that only a total of 105 female meioses were needed to transmit CHM*SAL from the putative founder to the youngest present day generation that was tested. ${ }^{41}$ This explains why, over a stretch totalling some $9 \mathrm{cM}$, very few recombinations have occurred (three documented by the study of 65 affected chromosomes).

A similar situation prevails regarding retinoschisis ( $R S$ ), another $\mathrm{X}$ linked recessive disorder causing progressive loss of vision in affected males. There are some 300 affected males in Finland (until recently the total number described in the rest of the world was less than 200 , but this may be mainly because of diagnostic difficulties ${ }^{13}$ ). The disease occurs in two main geographical clusters in Finland, in a densely populated region on the southwestern coast, and in the sparsely populated north-central part of the country (fig 4). Again haplotypes of flanking markers spanning almost $10 \mathrm{cM}$ are associated with the disease and the haplotypes in association are distinctly different in the two clusters. ${ }^{46}$ In this case the gene has not yet been cloned so the mutations are not known. The present data support a hypothesis predicting at least two independent mutations, each having expanded in Finland for some 10 to 20 generations.

In conclusion, linkage disequilibrium can be a major tool in the study of genes in isolated populations. As long as the number of generations since the founding is known, linkage disequilibrium can be used to assess the number of different mutations as well as genetic distances between loci. Conversely, if the genetic marker map is well characterised, the extent of linkage disequilibrium can be used to determine the number of generations since the founding.

\section{Autosomal recessive founding mutations}

Most of the autosomal recessive disorders that are common in Finland (table 1) occur with low frequency in other populations. Therefore the mutation rates of these genes are low and the high gene frequency in Finland is because of the chance inclusion or occurrence of one mutation in the small founding population followed by enrichment through genetic drift in the population that expanded while isolated. Repeated sampling within Finland in the form of bottlenecks and chance events contributed to the drift.

\section{CALCULATING THE PROPORTION OF THE} ANCESTRAL FOUNDING MUTATION AMONG ALL PRESENT DAY MUTATIONS

Given the characteristics of the Finnish population structure, the value of $\alpha=$ proportion of

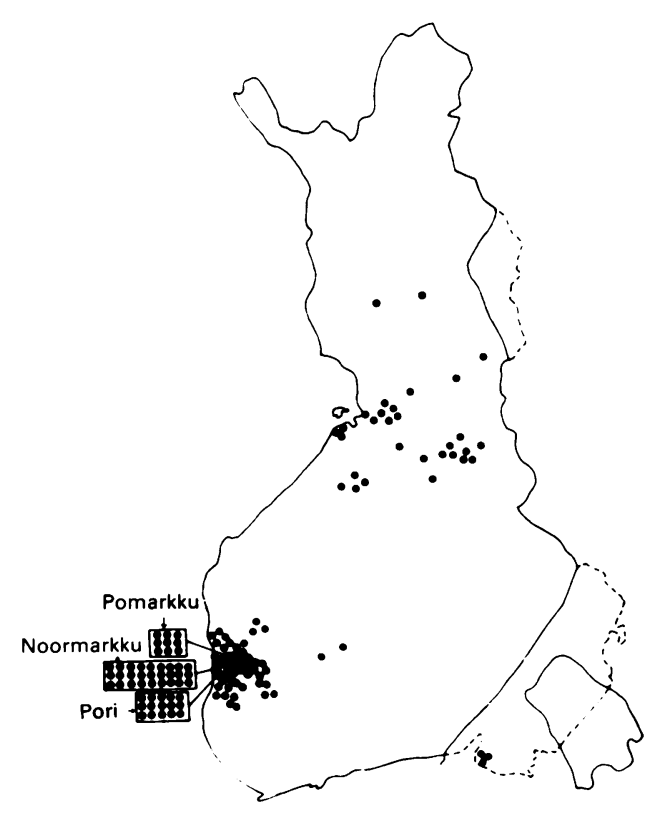

Figure 4 Map of Finland showing birth places of ancestors of patients with retinoschisis (from ref 3 ). 
mutations descending from the founding ancestor can be calculated. If

$\mu=$ the mutation rate at the disease locus

$\mathrm{g}=$ the number of generations since founding

$\mathrm{q}=$ the overall disease gene frequency, then

$\alpha=1-\mu \mathrm{gq}^{-1}$.

In the case of diastrophic dysplasia (DTD)

the above parameters can be determined with reasonable certainty. The mutation rate $\mu$ can be taken as approximately $5 \times 10^{-6}$ for a rare disease locus like DTD. The number of generations ( $\mathrm{g}$ ) since founding is approximated at 100 . Finally, the overall disease gene frequency $q$ can be calculated based on the frequency of newborn affected homozygotes; $q$ for DTD is estimated at $0.008 .^{47}$

With these approximations the value of $\alpha$ is 0.94 . In other words, out of $80000 \mathrm{DTD}$ bearing chromosomes in Finland, only $6 \%$ or some 5000 are the result of new mutations or immigration while the remaining $94 \%$ all descend from the original founder.

Table 5 lists the pertinent corresponding figures for four recessively inherited 'Finnish' disorders. The recent cloning of the AGA and OAT genes harbouring the disease causing mutations has allowed these mutations to be characterised so that the actual proportion of the main ancestral founding mutation is known. The numbers calculated in the way indicated above show good correlation with the actual ones (AGA: calculated 96\%, observed $98 \%$; OAT $90 \%$ v $85 \%$ ). For the remaining two diseases (DTD and EPM1) the genes have not yet been cloned so the mutations are unknown. Since in both cases the cloning of the gene is being actively pursued, ${ }^{4752}$ it will no doubt soon be possible to know how right or wrong the calculations are.

CALCULATING GENETIC DISTANCES BETWEEN DISEASE GENE AND MARKER LOCUS BASED ON LINKAGE DISEQUILIBRIUM

If

${ }^{\mathrm{P}}$ normal $=$ the frequency of an allele at a marker locus in normal chromosomes

$\mathrm{P}_{\text {affected }}=\mathrm{a}$ higher frequency of the same allele in chromosomes carrying the disease mutation,

then applying the Luria-Delbrück principle ${ }^{53}$ it follows that

$$
\begin{gathered}
(1-\Theta)^{\mathrm{g}}=\frac{{ }^{\mathrm{P}} \text { excess }}{\alpha} \\
\text { where }{ }^{\mathrm{P}} \text { excess }=\frac{{ }^{\mathrm{P}} \text { affected }-{ }^{\mathrm{P}} \text { normal }}{1-{ }^{\mathrm{P}} \text { normal }}
\end{gathered}
$$

When this equation was applied to the mapping of the DTD gene, which shows strong linkage disequilibrium with the CSF1R gene, a genetic distance of approximately $0.06 \mathrm{cM}$ was obtained. ${ }^{47}$ Similarly, in the case of EPM1, genetic distances between the disease gene and the closest marker loci of some $0.13 \mathrm{cM}$ to $0.30 \mathrm{cM}$ were calculated while other markers were further away..$^{52}$

In both instances the linkage disequilibrium data agreed both with the linkage mapping of the markers and with multipoint linkage analyses of the disease genes. Of note, by these conventional methods one could only assign the disease genes to intervals of some 7 to $10 \mathrm{cM}$ in genetic length. If the genetic distances calculated based on linkage disequilibrium turn out to be correct they have a resolution at least one order of magnitude greater than that achievable by conventional linkage analysis. This is an obvious advantage in the positional cloning of disease genes. That this degree of resolution can be achieved is of course the result of the fact that conventional linkage analysis is restricted to data on alleles in present living generations while linkage disequilibrium makes use of all meioses since the founding of the mutation in the population. Under circumstances such as high mortality caused by homozygosity for the disease gene, linkage disequilibrium may be the only feasible tool for mapping because it can be applied to families with only one affected child. In contrast, conventional linkage mapping requires multiplex families or a very large number of uniplex families.

\section{ACCURACY OF MAPPING BY LINKAGE DISEQUILIBRIUM}

Obviously there are many sources of error in this type of calculation. Even in isolated and well characterised populations such as the Finns some of the approximations and simplifications that need to be made for each disease may be wrong and this may lead to mistakes. For instance, by chance there may have been two founding mutations instead of one. If the two were independent, calculations of genetic distance would be skewed. The number of generations since the introduction of the mutation could be wrong by, say, a factor of 2 which would considerably affect the results. The same is true if the disease gene frequency in the population under study were seriously underestimated or, less likely, overestimated. However, in settings like the relatively centralised Finnish health care system and academic tradi-

Table 5 Calculated and observed present proportion of main mutation descending from one founding ancestor in the Finnish population. The number of generations from founding was taken as 100 and the mutation rate as $5 \times 106$ in

\begin{tabular}{|c|c|c|c|c|c|}
\hline \multirow[b]{2}{*}{ Disorder } & \multirow[b]{2}{*}{ Gene } & \multirow{2}{*}{$\begin{array}{l}\text { Overall } \\
\text { frequency of } \\
\text { disease allele }\end{array}$} & \multicolumn{2}{|c|}{$\begin{array}{l}\text { Present proportion of mutation } \\
\text { descending from the founding ancestor }\end{array}$} & \multirow[b]{2}{*}{ Reference } \\
\hline & & & Calculated (\%) & Observed (\%) & \\
\hline $\begin{array}{l}\text { Aspartylglucosaminuria } \\
\text { Gyrate atrophy of the choroid and retina } \\
\text { Diastrophic dysplasia } \\
\text { Progressive myoclonus epilepsy, } \\
\text { Unverricht-Lundborg type }\end{array}$ & $\begin{array}{l}\text { AGA } \\
\text { OAT } \\
\text { DTD } \\
\text { EPM1 }\end{array}$ & $\begin{array}{l}0.015 \\
0.005 \\
0.008 \\
0.005-0.008\end{array}$ & $\begin{array}{l}97 \\
90 \\
95 \\
90-95\end{array}$ & $\begin{array}{l}98 \\
85 \\
\text { ND } \\
\text { ND }\end{array}$ & $\begin{array}{l}48,49 \\
50,51 \\
47 \\
52\end{array}$ \\
\hline
\end{tabular}
all cases. 
tion of studying hereditary disorders, this is an unlikely major source of error. Mutation rates in genes causing diseases that are known to occur with low frequency world wide should typically be of the order of $5 \times 10^{-6}$ which was used in the calculations. However, this ignores the possible effect of selection, which can be hard to detect.

By contrast, mutation rates at anonymous marker loci apparently vary widely and need to be carefully assessed. Base changes responsible for the common two allele RFLPs have very low mutation rates. At the other extreme are certain simple sequence repeats. In the most commonly studied typical CA repeats mutation rates of $10^{-4}$ to $10^{-3}$ have been observed. ${ }^{54}$ However, in others the rate is higher, such as some tetranucleotide repeats, ${ }^{55}$ and the extraordinarily high rate of almost $0.5 \%$ documented in a CCTT repeat. ${ }^{47}$ It is possible that when detailed genetic mapping using linkage disequilibrium involving short sequence repeats is practised, the mutation rate of each marker must first be determined, for example, by studying CEPH families.

\section{THE REACH OF LINKAGE DISEQUILIBRIUM} MAPPING

Traditionally, in large panmictic populations, linkage disequilibrium is likely only at genetic distances well below $1 \mathrm{cM}$; however, few of the parameters necessary for calculating genetic distances are available in such populations. By contrast, Finland offers an ideal setting in that the population was founded sufficient time ago (say 100 generations) to have allowed many recombinations to occur, and has expanded to provide a population size large enough (now 5 million) to allow disease gene frequencies to be determined. In the absence of significant immigration during population expansion, the development of the haplotypes of markers surrounding the ancestral founding mutation can be monitored. Whenever the mutation or its expansion is recent, say 20 generations, haplotypes spanning as much as $10 \mathrm{cM}$ will be associated with the disease gene, providing evidence on genetic order and distances (if the number of generations is known) or the number of generations since the founding (if the genetic distances are known). The large reach of some $10 \mathrm{cM}$ of linkage disequilibrium mapping provides a unique opportunity in disorders where multiplex families are rare. This approach to mapping should be possible in many stable populations world wide.

In the case of autosomal recessive disorders whose mutations are geographically widespread in Finland, the founding must have occurred long ago. Using the approximation of 100 generations we have shown that the proportion of the founding ancestral mutation among all present existing mutations can be predicted well (table 5), indicating that at least in those cases, 100 generations is a reasonable assumption. Given this parameter, linkage disequilibrium allows genetic distances as small as a few hundredths of a centimorgan to be assessed. ${ }^{4752}$ This provides a powerful tool for genetic mapping at a resolution that cannot be achieved by any other method.

\section{Genetic drift works both ways}

If genetic drift and founder effects are mainly responsible for the observed high incidences of certain rare disease genes in the Finnish population (tables 1 and 2) then it follows that other rare disease genes should have very low frequencies produced by the same mechanisms. This is indeed the case. Perhaps the most illustrative examples are provided by phenylketonuria (PKU) and cystic fibrosis (CF). In spite of extensive searching and screening ${ }^{56}$ only eight PKU patients have been diagnosed in Finland, four of whom are alive at present. This suggests a gene frequency way below that of Finland's neighbours Sweden and Norway. Regarding CF, Finland's centralised health care system allows an accurate estimate of the number of CF patients; 20 living patients are known at present, the prevalence at birth of $1: 26000$ being roughly one-tenth that observed in Britain. ${ }^{57}$ Interestingly, only 18 out of the 40 Finnish CF chromosomes (45\%) carry the major $\Delta F 508$ mutation, which has led to speculation about another major mutation being a possibility. ${ }^{58}$ Such a mutation (394delTT) was recently discovered in 12 Finnish CF chromosomes, thus accounting for $30 \%$ of all CF mutations in the country..$^{59}$ Mutation 394delTT is also common in Scandinavia, ${ }^{60}$ it is rare in western Europe, while its frequency in Russia and the rest of eastern Europe remains to be determined. If it turns out to be common in the east, one might postulate that it spread to Scandinavia via Finland; if not, it may have a Scandinavian or Finnish origin.

As described by Norio $^{10}$ several well known recessively inherited diseases have apparently never been diagnosed in Finland. These include galactosaemia, maple syrup urine disease, cystinosis, histidinaemia, and Pendred syndrome. Other disorders that are so rare in Finns that they have been diagnosed only once or twice include Tay-Sachs disease, Gaucher disease, Hartnup disease, Fabry disease, and several glycogenoses.

In summary, the hypotheses regarding how certain rare disease mutations became highly enriched in Finland are amply supported by the fact that other rare disease mutations are extremely rare in Finland.

\section{Medical and social ramifications}

The impact of hereditary disorders on health care increases dramatically in modern medicine. Whenever a rare disorder is enriched in a population it is important that physicians are well informed about its existence, under what circumstances to expect it, and how to diagnose it. Many of the disorders described here are amenable to treatment if diagnosed in time. A single example, congenital chloride diarrhoea (CLD), will be mentioned. The main presenting symptom, watery diarrhoea in an infant, is so common that CLD will often be missed; 


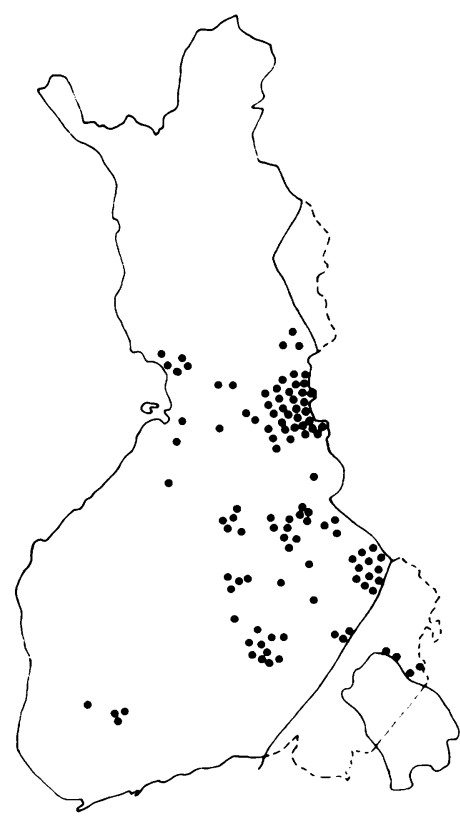

Figure 5 Map of Finland showing birth places of ancestors of patients with chloride diarrhoea (from ref 3).

however, when CLD is suspected the diagnosis is readily made by showing high chloride concentrations in the stools, and the life threatening condition is treated by chloride supplementation. As shown on the map of Finland (fig 5) the disease mainly occurs in the sparsely populated east central part of the country, where its incidence is high. As the disorder has been extensively studied it has also been the object of numerous seminars and presentations, particularly in the affected part of the country. As a result, its diagnosis and therapy pose few problems. Moreover, research into various aspects of the disease is facilitated by the high degree of ascertainment that follows from public and professional awareness of it.

It appears that family and patient acceptance, and participation in research, and therapeutic and preventive trials are all enhanced by the public recognition that a particular disorder occurs more commonly than elsewhere. As pointed out by Vogel and Motulsky, ${ }^{61}$ in relatively centralised health care systems of high quality, both the medical care and the scientific study of rare hereditary disorders can be vigorously pursued.

1 Hallman N, Hjelt L, Ahvenainen EK. Nephrotic syndrome in newborn and young infants. Ann Paediatr Fenn 1956;2:227-41.

2 Norio R. Heredity in the congenital nephrotic syndrome; a genetic study of 57 Finnish families with a review of reported cases. Ann Paediatr Fenn 1966;suppl 27:9-94.

3 Norio R, Nevanlinna HR, Perheentupa J. Hereditary diseases in Finland; rare flora in rare soil. Ann Clin Res 1973;5:109-41.

4 Nevanlinna HR. The Finnish population structure. A genetic and genealogical study. Hereditas 1972;71:195-236.

5 Workman PL, Mielke JH, Nevanlinna HR. The genetic structure of Finland. Am f Phys Anthropol 1976;44:34167.

6 Nevanlina HR. Genetic aspects of rare neurological disease. Acta Neurol Scand 1978;57(suppl 67):37-55.

7 Nevanlinna HR. Genetic markers in Finland. Haematologica 1980;13:65-74.

8 Virtaranta-Knowles $\mathrm{K}$, Sistonen $\mathrm{P}$, Nevanlinna HR. A population genetic study in Finland: comparison of the population genetic study in Finland: comparison of the
Finnish- and Swedish-speaking population. Hum Hered 1991;41:248-64.

9 Eriksson AW, Forsius HR, Nevanlinna HR, Workman PL,
Norio RK. Population structure and genetic disorders. London: Academic Press, 1980

10 Norio R. The diseases of Finland and Scandinavia. In Rotchild $\mathrm{H}$, ed. Biocultural aspects of disease. New York: Academic Press, 1981:359-415.

11 Markkanen $M$, Isaksson $R$, Norio $R$. Erikoista suvussamme-Suomalainen tautiperintö lyhyesti. Duodecim 1987;103:1434-63.

12 McKusick VA. Mendelian inheritance in man. Baltimore: Johns Hopkins University Press, 1992.

13 de la Chapelle A, Forsius $\mathrm{H}$, Alitalo T. X linked juvenile retinoschisis. In: Wright A, Jay B, eds. Molecular genetics of inherited eye disorders. Switzerland: Harwood Academic of inherited eye disorders.
Publishers, (in press).

14 Malafosse A, Lehesjoki AE, Genton P, et al. Identical genetic locus for Baltic and Mediterranean myoclonus. Lancet 1992;339:1080-1.

15 Tomaszewski L, Kulesza E, Socha J. Congenital chloride diarrhoea in Poland. Mat Med Pol 1987;4:271-7.

16 Lubani MM, Doudin KI, Sharda DC, et al. Congenital chloride diarrhoea in Kuwaiti children. Eur $\mathcal{f}$ Pediatr 1989;148:333-6.

17 Edgren T. Den förhistoriska tiden. In: Edgren T, Törnblom L, eds. Finlands historia. Part 1. Schildts: Ekenäs, 1992:11-270.

18 Sokal R, Oden NL, Wilson C. Genetic evidence for the spread of agriculture in Europe by demic diffusion. Nature 1991;351:143-5.

19 Meinander CF. Om svenskarnes inflyttningar till Finland. Historisk Tidskrift för Finland 1983;68:229-51.

20 Cavalli-Sforza LL. Genes, peoples and languages. Sci Am 1991;265:104-10.

21 Sokal RR, Jacques GM, Oden NL, et al. Genetic relationship of European populations reflect their ethnohistorical affinities. Am $\mathcal{F}$ Phys Anthropol 1993;91:55-70.

22 Vahtola J. The main phases of colonization in northern Finland. Faravid, Acta Societatis Historicae Finlandiae Septentrionalis. Finland: Jyvāskylā, 1993 (in press).

23 Harper PS. The epidemiology of Huntington's disease. Hum Genet 1992;89:365-76.

24 Meretoja J. Familial systemic paramyloidosis with lattice dystrophy of the cornea, progressive cranial neuropathy, skin changes and various internal symptoms: a previously unrecognized heritable syndrome. Ann Clin Res 1969;1:314-24.

25 Meretoja J. Genetic aspects of familial amyloidosis with corneal lattice dystrophy and cranial neuropathy. Clin Genet 1973;4:173-85.

26 Meretoja J. Tautiperintömme. Suomalainen amyloiditauti. f Finn Med Assoc 1976;31:2234-6.

27 Maury CPJ, Alli K, Baumann M. Finnish hereditary amyloidosis: amino acid sequence homology between the amyloid fibril protein and human plasma gelsolin. FEBS Lett 1990;269:85-7.

28 Maury CPJ, Baumann M. Isolation and characterisation of cardiac amyloid in familial amyloid polyneuropathy type IV (Finnish): relation of the amyloid protein to variant gelsolin. Biochim Biophys Acta 1990;1096:84-6.

29 Maury CPJ, Kere J, Tolvanen R, de la Chapelle A. Finnish hereditary amyloidosis is caused by a single nucleotide substitution in the gelsolin gene. FEBS Lett 1990;276:757.

30 de la Chapelle A, Kere J, Sack GH Jr, Tolvanen R, Maury CPJ. Familial amyloidosis, Finnish type: G654 to A mutation of the gelsolin gene in Finnish families and an mutation of the gelsolin gene in Finnish families and an

31 de la Chapelle A, Tolvanen R, Boysen G, et al. Gelsolinderived familial amyloidosis caused by asparagine or tyrosine substitution for aspartic acid at residue 187 . Nature Genet 1992;2:157-60.

32 Gorevic PD, Munoz PC, Gorgone G, et al. Amyloidosis due to a mutation of the gelsolin gene in an American family with lattice corneal dystrophy type II. $N$ Engl $\mathcal{f} \mathrm{Med}$ 1991;325:1780-5

33 de la Chapelle A, Sistonen P, Lehväslaiho H, Ikkala E, Juvonen E. Familial erythrocytosis genetically linked to erythropoietin receptor gene. Lancet 1993;2:32-4.

34 de la Chapelle A, Träskelin AL, Juvonen E. Truncated erythropoietin receptor causes dominantly inherited benign human erythrocytosis. Proc Natl Acad Sci USA 1993;90:4495-9.

35 Emanuel PD, Eaves CJ, Broudy VC, et al. Familial and congenital polycythemia in three unrelated families. Blood 1992;79:3019-30.

36 Kärnä J. Choroideremia. A clinical and genetic study of 84 Finnish patients and 126 female carriers. Acta Ophthalmol (Suppl) 1986;176:1-68.

37 Cremers FPM, van de Pol TJR, van Kerkhoff LPM, Wieringa B, Ropers HH. Cloning of a gene rearranged in patients with choroideremia. Nature 1990;347:674-7.

38 Schwartz M, Rosenberg T, van den Hurk JAJM, van de Pol DJR, Cremers FPM. Identification of mutations in Danish choroideremia families. Hum Mutat 1993;2:43-7.

39 McCulloch C, McCulloch RJP. A hereditary and clinical study of choroideremia. Trans Am Acad Ophthalmol Otolaryngol 1948;52:160-90.

40 Sankila EM, Tolvanen R, van den Hurk JAJM, Cremers FPM, de la Chapelle A. Aberrant splicing of the CHM gene is a significant cause of choroideremia. Nature Genet 1992;1:109-13.

41 Sankila EM, de la Chapelle A, Kärnä J, Forsius H, Frants R, Eriksson A. Choroideremia: close linkage to DXYS1 and DXYS12 demonstrated by segregation analysis and and DXYS12 demonstrated by segregation analysis and 22 . 
42 Sankila EM, Lehner T, Eriksson AW, et al. Haplotype and multipoint linkage analysis in Finnish choroideremia families. Hum Genet 1989;84:66-70.

43 Sankila EM, Sistonen P, Cremers F, de la Chapelle A Choroideremia: linkage analysis with physically mapped Choroideremia: linkage analysis with physically map
close DNA-markers. Hum Genet 1991;87:348-52.

44 Sankila EM, Tolvanen R, van den Hurk JAJM, Cremers FPM, de la Chapelle A. Choroideremia mutations in Finland. Abstract No 18, 25th Annual Meeting of the European Society of Human Genetics, 6-9 May 1993, Barcelona, Spain: 31 .

45 Hill WG, Robertson A. Linkage disequilibrium in finite populations. Theor Appl Genet 1968;38:226-31.

46 Alitalo T, Kruse TA, de la Chapelle A. Refined localization of the gene causing $\mathrm{X}$ linked juvenile retinoschisis. Genomics 1991;9:505-10.

47 Hästbacka J, de la Chapelle A, Kaitila I, Sistonen P, Weaver A, Lander E. Linkage disequilibrium mapping in isolated founder populations: diastrophic dysplasia in Finland. Nature Genet 1992;2:204-11.

48 Syvänen AC, Ikonen E, Manninen T, et al. Convenient and quantitative determination of the frequency of a mutant allele using solid-phase minisequencing: application to allele using solid-phase minisequencing: application to
aspartylglucosaminuria in Finland. Genomics aspartylglucosamin

49 Mononen T, Mononen I, Matilainen R, Airaksinen E. High prevalence of aspartylglucosaminuria among school-age children in eastern Finland. Hum Genet 1991;87:266-8.

50 Mitchell GA, Brody LC, Sipilä I, et al. At least two mutant alleles of ornithine $\delta$-aminotransferase cause gyrate atrophy of the choroid and retina in Finns. Proc Natl Acad Sci USA 1989;86:197-220.
51 Brody LC, Mitchell GA, Obie C, et al. Ornithine $\delta$ aminotransferase mutations in gyrate atrophy. $\mathcal{f}$ Biol Chem 1992;267:3302-7.

52 Lehesjoki AE, Koskiniemi M, Norio R, et al. Localization of the EPM1 gene for progressive myoclonus epilepsy on chromosome 21: linkage disequilibrium allows high resolution mapping. Hum Mol Genet (in press).

53 Luria SE, Delbrück M. Mutations of bacteria from virus sensitivity to virus resistance. Genetics 1943;28:491-511.

54 Weissenbach J, Gyapay G, Dib C, et al. A secondgeneration linkage map of the human genome. Nature 1992;359:794-801.

55 Weber JL, Wong C. Mutation of human short tandem repeats. Hum Mol Genet (in press).

56 Visakorpi JK, Palo J, Renkonen OV. The incidence of PKU in Finland. Acta Paediatr Scand 1971;60:666-8.

57 Kere J, Norio R, Savilahti E, Estivill X, de la Chapelle A. Cystic fibrosis in Finland: a molecular and genealogical study. Hum Genet 1989;83:20-5.

58 Kere J, Savilahti E, Norio R, Estivill X, de la Chapelle A. Cystic fibrosis mutation d508 in Finland: other mutation predominate. Hum Genet 1990;85:413-15.

59 Kere J, Estivill X, Chillón M, et al. Cystic fibrosis in a lowincidence population: two major mutations in Finland. Hum Genet (in press).

60 Schwartz M, Anvret M, Claustres M, et al. 394delTT: a Nordic cystic fibrosis mutation. Hum Genet (in press).

61 Vogel F, Motulsky AG. Human genetics. 2nd ed. Berlin: Springer-Verlag, 1986:509-11. 